\title{
Cardiovascular risk factors in Mexico and the United States: A comparative cross-sectional study between the HABLE and MHAS participants
}

\author{
Raúl Vintimilla, * Miguel Reyes, Leigh Johnson, James Hall and Sid O’Bryant
}

University of North Texas, Health Science Center, Institute for Translational Research, Texas, United States

\begin{abstract}
Introduction: In the United States, information on the Mexican-American population is available through the Health and Aging Brain among Latino Elders (HABLE) study; in Mexico, the results of the Mexican Health and Aging Study (MHAS) are available. Objective: To compare the prevalence of cardiovascular risk factors between men and women of the HABLE and MHAS studies. Method: The prevalence of hypertension, diabetes, hypercholesterolemia and abdominal obesity was transversely analyzed in 559 HABLE participants and compared with data from 13,663 MHAS participants. The comparison was made using Student's t-test and the chi-square test, according to the type of variable. Results: The analysis showed that the prevalence of hypertension ( $50 \%, 95 \% \mathrm{Cl}=41.8-51.8)$, diabetes $(35.5 \%, 95 \% \mathrm{Cl}=27.6-43.8)$ and abdominal obesity (59.3\%, $95 \% \mathrm{Cl}=50.5-68.1)$ were significantly higher in HABLE males, whereas females had a higher prevalence of diabetes (36.8\%, $95 \% \mathrm{Cl}=32.2-41.5)$ and abdominal obesity $(89.6 \%, 95 \% \mathrm{Cl}=86.6-92.5)$. Hypercholesterolemia had a higher prevalence in MHAS females (53.3 \%, $95 \% \mathrm{Cl}=50.3-56.2)$. Conclusion: The prevalence of cardiovascular risk factors was higher in Mexican-American HABLE participants, than in Mexican MHAS participants.
\end{abstract}

KEY WORDS: Cardiovascular disease. Risk factors. Mexico. Mexican-Americans.

\section{Factores de riesgo cardiovascular en Estados Unidos y México: comparación de los estudios HABLE y ENASEM}

\section{Resumen}

Introducción: En Estados Unidos se dispone de información acerca de la población mexicoamericana por el Estudio de Salud y Envejecimiento del Cerebro en Latinos Mayores (HABLE); en México se dispone de los resultados del Estudio Nacional de Salud y Envejecimiento en México (ENASEM). Objetivo: Comparar la prevalencia de factores de riesgo cardiovascular entre hombres y mujeres de HABLE y ENASEM. Método: Se analizó transversalmente la prevalencia de hipertensión, diabetes, hipercolesterolemia y obesidad abdominal en 559 participantes de HABLE y se comparó con datos de 13663 participantes del ENASEM. La comparación se realizó mediante t de Student y chi cuadrada, según el tipo de variable. Resultados: El análisis demostró que la prevalencia de hipertensión (50\%, IC $95 \%=41.8-51.8)$, diabetes (35.5\%, IC $95 \%=$ 27.6-43.8) y obesidad abdominal (59.3\%, IC $95 \%=50.5-68.1)$ fueron significativamente mayores en hombres del HABLE, mientras que las mujeres presentaron una prevalencia más elevada de diabetes $(36.8 \%$, IC $95 \%=32.2-41.5)$ y obesidad abdominal (89.6 \%, IC $95 \%$ = 86.6-92.5). La hipercolesterolemia tuvo una prevalencia más elevada en mujeres del ENASEM (53.3 \%, IC $95 \%$ = 50.3-56.2). Conclusión: La prevalencia de factores de riesgo cardiovascular fue mayor en mexicoamericanos participantes del HABLE, que en mexicanos participantes del ENASEM.

PALABRAS CLAVE: Enfermedad cardiovascular. Factores de riesgo. México. Mexicoamericanos.
Correspondence:
Date of reception: 19-06-2019
Gac Med Mex. 2020;156:16-20
${ }^{*}$ Raúl Vintimilla
Date of acceptance: 01-07-2019
Contents available at PubMed
E-mail: raul.vintimilla@unthsc.edu
DOI: 10.24875/GMM.M19000316
www.gacetamedicademexico.com
0016-3813/@ 2019 Academia Nacional de Medicina de México, A.C.. Published by Permanyer. This is an open access article under the CC BY-NC-ND license (http://creativecommons.org/licenses/by-nc-nd/4.0/). 


\section{Introduction}

In the United States, the main causes of death are heart conditions, cancer and unintentional injuries. ${ }^{1}$ In Mexican-Americans, which constitute $63.4 \%$ of Latinos in that country, ${ }^{2}$ cancer is the leading cause, followed by heart conditions and unintentional injuries. ${ }^{3}$ Data from the National Institute of Statistics and Geography of Mexico (INEGI - Instituto Nacional de Estadística y Geografía) show that heart conditions, diabetes and cancer are the top three causes of death in Mexico. ${ }^{4}$ Since several years ago, the World Health Organization has determined that approximately $31 \%$ of all recorded deaths are due to cardiovascular diseases, which constitute the leading cause of death worldwide. ${ }^{5}$

Due to the increase in life expectancy at birth, a larger percentage of people age and develop cardiovascular diseases, ${ }^{6}$ but there are several risk factors such as systemic arterial hypertension, diabetes mellitus, dyslipidemias and obesity, which can be measured, modified or controlled. ${ }^{7}$ Studies conducted in Mexican-Americans (subjects born in Mexico living in the United States and subjects of Mexican ancestry born in the United States), such as the San Antonio Heart Study or the Hispanic Community Health Study/ Study of Latinos, have demonstrated that the prevalence of cardiovascular risk factors (CVRF) is higher in Mexican-Americans than in non-Hispanic whites. ${ }^{8,9}$

In Mexico, the 2012 National Health and Nutrition Survey reported an elevated prevalence of CVRF in the general population, ${ }^{10}$ which is consistent with the results of the CARMELA trial ${ }^{11}$ and of the study carried out by Orozco González et al. in a sample of health workers in two hospitals of the Mexican Institute of Social Security. ${ }^{12}$

Several researchers have suggested that the years of residence in the United States, the language spoken at home and other behavioral changes negatively impact Mexican-Americans lifestyle, and place this population at higher risk of developing CVRF. ${ }^{13,14}$ However, due to methodological limitations and inconsistency in the methods used to quantify these variables, data are contradictory.

In the present analysis, we compare the prevalence of CVRF in a sample of Mexican-Americans residing in the United States, part of the Health and Aging Brain among Elderly Latinos (HABLE) study, with a sample of the Mexican Health and Aging Study (MHAS). The hypothesis was that Mexican-Americans have a higher prevalence of cardiovascular risk factors than their Mexican counterparts. Understanding the similarities and differences in the distribution of these risk factors on both sides of the border is important in order to develop and implement effective prevention measures.

\section{Method}

Epidemiological, descriptive, cross-sectional study of two populations taken from two longitudinal studies: HABLE in the United States and MHAS in Mexico. HABLE analyzes the relationship of different biological factors and diseases such as diabetes, hypertension, depression, etc., with changes in memory, knowledge and aging in Mexican-Americans and non-Hispanic whites. HABLE has been ongoing since 2012 at the Health Science Center of the University of North Texas, in Fort Worth, Texas; it recruits subjects older than 50 years directly from the community, through community recruiters, presentations, press releases, announcements and word of mouth information. The participants undergo a detailed interview on demographic and health information, neuropsychological assessment tests, fasting blood clinical tests, anthropometric measurements and a medical evaluation.

In turn, MHAS is a national longitudinal study in Mexico that has been ongoing since 2001. The interview and data collection are carried out in people older than 50 , from urban and rural areas of the 32 states of the country. This study is a collaboration between the University of Texas Medical Branch in Galveston, Texas, the National Institute of Statistics and Geography and the National Institute of Public Health of Mexico. MHAS is investigating diseases and disability associated with aging and assessing the effects of individual behavior, migration, socioeconomic status and community health characteristics. ${ }^{15}$ The MHAS questionnaire includes information on demographic data, general health status, chronic conditions, socioeconomic status, migration, family structure and housing condition. Anthropomorphic measurements, blood tests and neuropsychological tests were carried out in a subsample of participants. ${ }^{16}$

Both investigations adhered to the relevant ethical conditions for research in human beings and were approved by the corresponding ethics committee. All participants signed an informed consent form.

Between May 2012 and June 2015, 771 participants were admitted to the HABLE study, out of 
Table 1. Demographic characteristics according to gender

\begin{tabular}{|c|c|c|c|c|c|c|c|c|}
\hline & \multicolumn{4}{|c|}{ Men } & \multicolumn{4}{|c|}{ Women } \\
\hline & \multicolumn{2}{|c|}{ HABLE $(n=138)$} & \multicolumn{2}{|c|}{ MHAS ( $n=5786)$} & \multicolumn{2}{|c|}{ HABLE $(n=421)$} & \multicolumn{2}{|c|}{ MHAS $(n=7877)$} \\
\hline & \multicolumn{2}{|c|}{ Mean \pm SD } & \multicolumn{2}{|c|}{ Mean \pm SD } & \multicolumn{2}{|c|}{ Mean \pm SD } & \multicolumn{2}{|c|}{ Mean \pm SD } \\
\hline Age (years) & \multicolumn{2}{|c|}{$63.9 \pm 8.3$} & \multicolumn{2}{|c|}{$68.2 \pm 15.5$} & \multicolumn{2}{|c|}{$60.4 \pm 8.2$} & \multicolumn{2}{|c|}{$67.0 \pm 17.8$} \\
\hline Education (years) & \multicolumn{2}{|c|}{$7.7 \pm 4.8$} & \multicolumn{2}{|c|}{$6.1 \pm 5.8$} & \multicolumn{2}{|c|}{$7.7 \pm 4.2$} & \multicolumn{2}{|c|}{$5.2 \pm 5.1$} \\
\hline Marital status married & $\mathrm{n}$ & $\%$ & $\mathrm{n}$ & $\%$ & n & $\%$ & $\mathrm{n}$ & $\%$ \\
\hline Yes & 103 & 74.6 & 4580 & 87.8 & 202 & 48.2 & 4323 & 72.6 \\
\hline No & 33 & 25.4 & 636 & 12.2 & 217 & 51.8 & 1630 & 27.4 \\
\hline
\end{tabular}

HABLE $=$ Health \& Aging Brain among Latino Elders, MHAS = Mexican Health and Aging Study.

Table 2. Prevalence of cardiovascular risk factors for the male gender

\begin{tabular}{|c|c|c|c|c|c|c|c|}
\hline & \multicolumn{3}{|c|}{ HABLE } & \multicolumn{3}{|c|}{ MHAS } & \multirow[t]{2}{*}{$\mathbf{p}^{*}$} \\
\hline & $\mathrm{n}$ & $\%$ & $95 \% \mathrm{Cl}$ & $\mathrm{n}$ & $\%$ & $95 \% \mathrm{Cl}$ & \\
\hline Hypertension & 138 & 50.0 & $41.8-51.8$ & 5786 & 41.2 & $39.9-42.4$ & 0.03 \\
\hline Diabetes & 138 & 35.5 & $27.6-43.8$ & 5786 & 22.4 & $21.2-23.4$ & 0.0003 \\
\hline Hypercholesterolemia & 138 & 34.8 & $26.7-42.8$ & 770 & 40.6 & $37.1-44.1$ & 0.2 \\
\hline Abdominal obesity & 138 & 59.3 & $50.5-68.1$ & 767 & 37.9 & $34.5-41.3$ & $<0.0001$ \\
\hline
\end{tabular}

${ }^{*}$ Chi-square test. HABLE $=$ Health \& Aging Brain among Latino Elders, MHAS $=$ Mexican Health and Aging Study.

Table 3. Prevalence of cardiovascular risk factors for the female gender

\begin{tabular}{|c|c|c|c|c|c|c|c|}
\hline & \multicolumn{3}{|c|}{ HABLE } & \multicolumn{3}{|c|}{ MHAS } & \multirow[t]{2}{*}{$p^{*}$} \\
\hline & $\mathbf{n}$ & $\%$ & $95 \% \mathrm{Cl}$ & $\mathbf{n}$ & $\%$ & $95 \% \mathrm{Cl}$ & \\
\hline Hypertension & 421 & 50.6 & $45.9-55.5$ & 7877 & 54.3 & $53.2-55.4$ & 0.1 \\
\hline Diabetes & 421 & 36.8 & $32.2-41.5$ & 7877 & 27.5 & $26.5-28.4$ & $<0.0001$ \\
\hline Hypercholesterolemia & 421 & 45.8 & $41.0-50.6$ & 1083 & 53.3 & $50.3-56.2$ & 0.009 \\
\hline Abdominal obesity & 421 & 89.6 & $86.6-92.5$ & 1112 & 77.0 & $74.5-79.4$ & $<0.0001$ \\
\hline
\end{tabular}

${ }^{*}$ Chi-square test. HABLE $=$ Health \& Aging Brain among Latino Elders, MHAS = Mexican Health and Aging Study.

which 559 were of Mexican origin (138 men and 421 women), residents of the Dallas-Fort Worth, Texas area; their data were used for the analysis. The age range was 50 to 85 years. For the analysis of the Mexican population, the free database of the third MHAS 2012 round was accessed. ${ }^{17}$ During this round, 18,465 interviews were conducted. Final analysis on diabetes and hypertension was carried out in 13,663 participants (5,786 men and 7,877 women) and total cholesterol and abdominal obesity analysis was conducted in a subsample of 1,882 participants (1,112 women). The age range was 50 to 110 years.

The diagnosis of hypertension and diabetes mellitus was imputed based on previous medical diagnosis self-report or on the use of medications for these two pathologies. According to established standards, high cholesterol levels were considered at values $>200 \mathrm{mg} / \mathrm{dL}$ and abdominal obesity as a waist circumference $>40$ inches in men and > 35 inches in women.

\section{Statistical analysis}

A descriptive analysis of all study variables was carried out. Demographic characteristics are presented as the mean \pm standard deviation for continuous variables and as frequency and percentage for categorical variables. The prevalence of CVRF was established. Prevalence is reported in percentages with a $95 \%$ confidence interval. The comparison between groups was made using Student's t-test for continuous variables and the chi-square test for categorical variables. 
The analysis was divided by gender. A p-value $\leq 0.05$ was considered significant. The SPSS statistical program for Windows, version 23 (SPSSW Inc., Chicago, IL), was used for the analysis.

\section{Results}

MHAS men and women had a higher mean age than the participants of the HABLE study (68.2 and 67.0, respectively) (Table 1). HABLE participants had a higher level of education, with a mean of 7.7 years both in men and women. Eighty-eight and $75 \%$ of men in MHAS and HABLE reported being married; in women, the difference was larger: $73 \%$ versus $48 \%$, in MHAS and HABLE, respectively. It should be noted that all differences between the samples were statistically significant $(p \leq 0.05)$.

The prevalence of CVRF in men is shown in Table 2. The prevalence of hypertension was $50 \%(95 \%$ $\mathrm{Cl}=41.8-51.8)$, of diabetes $35.5 \%(95 \% \mathrm{Cl}=27.6-43.8)$ and of abdominal obesity $59.3 \%(95 \% \mathrm{Cl}=50.5-68.1)$, with the analysis showing that the prevalence of these conditions in HABLE men was significantly higher than in MHAS males. As for hypercholesterolemia, the difference between men in both studies was not statistically significant $(p=0.2)$.

The prevalence of diabetes and abdominal obesity was also significantly higher in HABLE women, with 36.8 $\%(95 \% \mathrm{Cl}=32.2-41.5)$ and $89.6 \%(95 \% \mathrm{Cl}=86.6$ 92.5), respectively, in comparison with their MHAS counterpart (Table 3). As for hypercholesterolemia, the prevalence was significantly higher in MHAS women, with $53.3 \%(95 \% \mathrm{Cl}=50.3-56.2)$. The difference in the prevalence of hypertension between women in both studies was not statistically significant $(p=0.1)$.

\section{Discussion}

The results of our study suggest that MHAS participants have a lower prevalence of CVRF than HABLE participants. HABLE men had a higher prevalence of hypertension, diabetes and abdominal obesity than MHAS men. Among women, the percentage with diabetes and abdominal obesity was also higher in HABLE in comparison with the MHAS participants. The results were not modified when level of education and marital status were included in the models.

Not all risk factors were higher in women in the United States study. The percentage of women with high cholesterol levels was higher in MHAS women; the explanation for this could lie in the type of diet or in the level of physical activity. This is consistent with studies that suggest that Latinos with low levels of acculturation in the United States are at higher risk for poorly controlled hypercholesterolemia, ${ }^{18}$ and it has even been suggested that the only CVRF that improves with high degrees of acculturation is dyslipidemia. ${ }^{19}$ In any case, more detailed research is required in order to elucidate these findings.

The results of our study are consistent with those of other authors, who suggest that Mexicans residing in Mexico are at lower risk for developing CVRF than those living in the United States and their descendants. ${ }^{20,21}$ Although the findings of several analyses have been contradictory, in general, attempts have been made to relate them to the degree of acculturation. Acculturation is defined as the process whereby immigrants adopt the culture, beliefs and practices of the place they reside in. ${ }^{22}$ It has been suggested that the higher the degree of acculturation, the higher the risk for developing CVRF. The explanation might be that these subjects adopt less healthy behaviors, ${ }^{23}$ as well as the high levels of psychological stress associated with immigration. ${ }^{24}$ It has even been observed that Mexicans living near the US border have a higher risk of mortality associated with cardiovascular problems when compared with inhabitants of other regions of Mexico, ${ }^{25}$ possibly due to the proximity and influence of the culture on the other side of the border.

There are several limitations in this study: due to its cross-sectional design, it is not possible to assess the effect that diet, physical activity, and stress exert on the prevalence of CVRF; the diagnosis of diabetes and hypertension relied on participants' self-report, which could have caused an underestimation of the prevalence of these factors; in addition, the analyses were not controlled for other confounding variables such as socioeconomic status, access to health services or use of medications, which might have an important effect on the prevalence of CVRF. Some of the strengths of this study include the similarity between both samples: both included community-dwelling subjects who were randomly selected.

\section{Conclusions}

Our study contributes to the scarce literature on the prevalence of cardiovascular risk factors on both sides of the border. Our analysis suggests that the prevalence of CVRF was higher in Mexican-Americans enrolled in the HABLE study, than in Mexicans participating in the MHAS study. New studies are needed in order to investigate cardiovascular 
problems in Mexicans from both countries, using representative samples and with similar demographic and socioeconomic characteristics. A better insight on these cardiovascular risk factors should lead to the design of interventions aimed at preventing and counteracting the effect these factors have on the health of Mexicans and Mexican-Americans.

\section{Acknowledgements}

The research herein reported was supported by the National Institute on Aging, which is part of the National Institutes of Health. The content is the responsibility of the authors and does not necessarily represent the official vision of the National Institutes of Health. The research team would like to thank Fort Worth local community and the HABLE and MHAS participants. The data and documentation files are for public use and are available at www.ENASEM.org

\section{Funding}

HABLE is funded by the National Institute on Aging, which belongs to the National Institutes of Health of the United States, with grant number R01AG054073. MHAS is partially funded by the National Institutes of Health/National Institute on Aging (NIHR01AG018016) and by INEGI.

\section{Conflict of interests}

The authors declare that they have no conflicts of interest.

\section{References}

1. National Center for Health Statistics. Mortality in the United States, 2017. Data Brief No. 328, Noviembre 2018 [en línea]. EE. UU.: Centers for Disease Control and Prevention; 2018.

2. Office of Minority Health [en línea]. EE. UU.: U.S. Department of Health and Human Services; 2019.

3. Heron M. Deaths: leading Causes for 2016. Natl Vital Stat Rep. 2018; 67:1-77.

4. Características de las defunciones registradas en México durante 2017. México: Instituto Nacional de Estadística y Geografía; 2018.
5. Enfermedades cardiovasculares [en línea]. Ginebra: Organización Mundial de la Salud; 2019

6. Las enfermedades cardiovasculares: un problema de salud pública y un reto global. Biomédica. 2011;31.

7. Sánchez-Arias AG, Bobadilla-Serrano ME, Dimas-Altamirano B, Gómez-Ortega M, González-González G. Enfermedad cardiovascular: primera causa de morbilidad en un hospital de tercer nivel. Rev Mex Cardiol. 2016;27:s98-s102.

8. Hunt KJ, Resendez RG, Williams K, Haffner SM, Stern MP, Hazuda H. All-cause and cardiovascular mortality among Mexican American and non-Hispanic white older participants in the San Antonio Heart Study-evidence against the "Hispanic paradox". Am J Epidemiol. 2003;158: 1048-1057.

9. Daviglus ML, Talavera GA, Avilés-Santa ML, Allison M, Cai J, Criqui MH, et al. Prevalence of major cardiovascular risk factors and cardiovascular diseases among Hispanic/Latino individuals of diverse backgrounds in the United States. JAMA. 2012;308:1775-1785.

10. Encuesta Nacional de Salud y Nutrición (ENSANUT) 2012. México: Instituto Nacional de Salud Pública/Secretaría de Salud; 2013.

11. Schagrodsky H, Hernández-Hernández R, Champagne BM, Silva $H$, Vinueza R, Silva Aycaguer LC, et al. CARMELA: assessment of cardiovascular risk in seven Latin American cities. Am J Med. 2008:121:58-65.

12. Orozco-González CN, Cortés-Sanabria L, Viera-Franco JJ, Ramírez-Márquez JJ, Cueto-Manzano AM. Prevalencia de factores de riesgo cardiovascular en trabajadores de la salud. Rev Med Inst Mex Seguro Soc. 2016;54:594-601.

13. Vaeth PAC, Willet DL. Level of acculturation and hypertension among Dallas County Hispanics: findings from the Dallas Heart Study. Ann Epidemiol. 2005;15:373-380.

14. Eamranond PP, Legedza A TR, Diez-Roux AV, Kandula NR, Palmas W, Siscovick DS, et al. Association between language and risk factor levels among Hispanic adults with hypertension, hypercholesterolemia, or diabetes. Am Heart J. 2009;157:53-59.

15. Estudio Nacional de Salud y Envejecimiento en México. México: Instituto Nacional de Estadística y Geografía/Universidad de Pennsylvania/ Universidad de Maryland/Universidad de Wisconsin; 2015.

16. Wong R, Michaels-Obregon A, Palloni A. Cohort Profile: The Mexican Health and Aging Study (MHAS). Int J Epidemiol. 2017:46:1-10.

17. Mex-Cog, Estudio sobre Envejecimiento Cognitivo Vinculado al ENASEM, [2012]. Archivos de Datos y Documentación (uso público). Mex-Cog [Sección A, Sección C, Sección L]. Consultado 2019 mar 20.

18. Eamranond PP, Wee CC, Legedza AT, Marcantanio ER, Leveille SG. Acculturation and cardiovascular risk factor control among Hispanic adults in the United States. Public Health Rep. 2009;124:818-824.

19. López L, Peralta CA, Lee A, Zeki-Al Hazzouri A, Hann MN. Impact of acculturation on cardiovascular risk factors among elderly Mexican Americans. Ann Epidemiol. 2014; 24:714-719.

20. Abraído-Lanza AF, Chao MT, Flórez KR. Do healthy behaviors decline with greater acculturation? Implications for the Latino mortality paradox. Soc Sci Med. 2005;61:1243-1255.

21. Lara M, Gamboa C, Kahramanian MI, Morales LS, Bautista DE. Acculturation and Latino health in the United States: a review of the literature and its sociopolitical context. Annu Rev Public Health. 2005;26:367-397.

22. Thomson MD, Hoffman-Goetz L. Defining and measuring acculturation: A systematic review of public health studies with Hispanic populations in the United States. Soc Sci Med. 2009;69:983-991.

23. Dixon LB, Sundquist J, Winkleby M. Differences in energy, nutrient, and food intakes in a US sample of Mexican American women and men: findings from the Third National Health and Nutrition Examination Survey, 1988-1994. Am J Epidemiol. 2000;152:548-557.

24. Finch B, Vega WA. Acculturation stress, social support, and self-rated health among Latinos in California. J Immigr Health. 2003;5:109-117.

25. Anaya G, Al-Delaimy WK. Effect of the US-Mexico border region in cardiovascular mortality: ecological time trend analysis of Mexican border and non-border municipalities from 1998 to 2012. BMC Public Health. 2017;17:400. 